$\underline{\text { Research Article }}$

\title{
IN VITRO PENETRATION TESTS OF TRANSETHOSOME GEL PREPARATIONS CONTAINING CAPSAICIN
}

\author{
NURAINI AZIZAH, ERNY SAGITA, ISKANDARSYAH ISKANDARSYAH* \\ Department of Pharmacy, Faculty of Pharmacy, Universitas Indonesia, Jakarta, Indonesia. Email: aya_2803@yahoo.com
}

Received: 21 April 2017, Revised and Accepted: 13 July 2017

\section{ABSTRACT}

Objective: Capsaicin is an active compound found in chili pepper and has been shown to have analgesic, antioxidant, anticancer, and anti-obesity properties. To improve its penetration into the skin, capsaicin was prepared in a transethosome vesicle. Importantly, transethosomes are vesicles that consist of phosphatidylcholine, surfactant, and ethanol. In this study, capsaicin was prepared in a transethosome vesicle using two different methods: Direct transethosome formation and thin layer hydration. The aims of this study were to determine the effects of various methods of transethosome formation on capsaicin characteristics and to evaluate the penetration capabilities of transethosome capsaicin gel.

Methods: Ultimately, transethosome formation via the thin layer method yielded more favorable characteristics; these formations had particle sizes of $174.9 \pm 2.02 \mathrm{~nm}$ and an entrapment efficiency of $84.85 \pm 1.15 \%$. The transethosome suspension was then developed into a gel formulation using $1 \%$ carbomer. An in vitro penetration test was performed using a Franz diffusion cell of mice abdomen skin, and the performance of the transethosome capsaicin gel was compared to that of the standard capsaicin gel.

Results: Penetration rate of capsaicin from either the transethosome gel preparation and the standard gel substance was $1549.68 \pm 49.6$ and $846.05 \pm 10.1 \mu \mathrm{g} / \mathrm{cm}^{2}$, respectively.

Conclusions: According to these results, it can be concluded that gel preparations containing transethosome increase capsaicin penetration into the skin.

Keywords: Capsaicin, Franz diffusion cell, Gel, Penetration, Transethosome.

(C) 2017The Authors.Published by Innovare Academic Sciences PvtLtd. Thisisan open accessarticle under the CC BYlicense (http://creativecommons. org/licenses/by/4. 0/) DOI: http://dx.doi.org/10.22159/ijap.2017.v9s1.68_75

\section{INTRODUCTION}

According to the WHO statistics, 1.9 billion people across the world were overweight in 2012, and approximately 600 million people suffered from clinical obesity. An overweight individual typically has excessive fat stores in his or her body. This excessive accumulation of fat can cause various problems such as obesity, cardiovascular disease, diabetes, and esthetic problems including cellulite and corpulence [1]. Capsaicin (8-methyl-N-vanillyl-trans-6-nonenamide) is an active compound contained in chili pepper and has been shown to have analgesic, antioxidant, anticancer, and anti-obesity properties. A recent systematic review reported that the consumption of capsaicin increases energy expenditures by about $50 \mathrm{kcal} /$ day, which in turn leads to clinically significant weight loss over 1-2 years [2]. It was also observed that the regular use of capsaicin significantly reduced abdominal adipose tissue levels and decreased appetite and energy intake [2]. Capsaicin prepared in transfersome in a $0.075 \%$ concentration has been used to maximize capsaicin intake in small dosages, thus increasing skin penetration and effectiveness of capsaicin [3].

Transethosome is a microparticle carrier and an ultradeformable lipid vesicle that is based on transfersome and ethosome [4]. Transethosomes consist of phospholipids, water, ethanol, and an edge activator (EA) or penetration enhancer. Importantly, phospholipids can interact with stratum corneum, improve tissue hydration, merge with lipids from the stratum corneum, and enhance penetration. The presence of an EA enables the vesicle to deform without losing structural integrity. The combination of ethanol and an EA causes a rearrangement of the lipid bilayer of these vesicles [5]. Notably, transethosomes can be produced using either the transfersome or ethosome method. In 2014, Shaji and Garude engaged in transethosome production using the direct method, which is both simpler and faster. The direct method does not require a heating process and therefore can be used with thermolabile compounds. In addition, in 2015, Man Ma undertook a transethosome production project that utilized the thin layer method and developed a vesicle with good entrapment and spherical shape [6,7]. This study seeks to determine which method is best by studying transethosome vesicles. Ultimately, the best method will be used to formulate a gel compound. In addition, the penetration of transethosome gel will be compared to that of non-transethosome gel via a Franz diffusion cell.

\section{METHODS}

\section{Instruments}

The following instruments were used over the course of this study: An analytic scale (Sartorius), a Franz cell diffusion tool (Bengkel Gelas, Indonesia), a rotary evaporator (Hahn Shin HS-2005s-N), an evaporator vacuum (Janke and Kunkel IKA, Germany), a vortex (As One), a sonicator (Branson 3200), a homogenizer (Edmund Bühler, Germany), a ultraviolet-visible (UV-Vis) spectrophotometer (Shimadzu UV-1800, Japan), a pH meter (Eutech Instrument pH 510, Singapore), a dynamic light scattering (DLS) particle size analyzer (Malvern Zetasizer), a viscometer (Brookfield, USA), a mini extruder set (Avanti Polar Lipids), a polycarbonate membrane $0.1 \mu \mathrm{m}$ (Whatman), a transmission electron microscope (TEM) (Tecnai F20, the Netherlands, and JEOL JEM-1010), a centrifuge tube with a 5000 Dafilter, and various other glass wares.

\section{Materials}

The following materials were used during this study: Synthetic capsaicin (Phayno Industry, China), phosphatidylcholine (phospholipon 90G) (Lipoid, Germany), carbomer (Lubrizol, Korea), span 80 (Dow Chemical Co.), triethanolamine (Croda, Singapore), sodium hydroxide (Merck, Germany), potassium dihydrogen phosphate (Merck, Germany), 
distilled water (Brataco, Indonesia), ethanol (Merck, Germany), dichloromethane (Merck, Germany), and methanol (Merck, Germany).

\section{Animals}

The following animals were used in the completion of this study: Female white rats of the Sprague Dawley strain, 2-3 months old, with weights of between 150 and $200 \mathrm{~g}$ (Botanical Agricultural Institute, Indonesia).

\section{Transethosome production}

\section{Direct method}

The compositions of all transethosome formulations are shown in Table 1. Phospholipon 90G, capsaicin, and span 80 were dissolved in ethanol in a conical flask. An aqueous phase was then added to the alcoholic phase and mixed in a homogenizer at 700-1000 rpm for 5 minutes.

\section{Hydration thin layer method}

The transethosome formulations of capsaicin prepared via the thin film method are described in Table 1. During this process, phospholipids and surfactants were dissolved in $25 \mathrm{~mL}$ of dichloromethane. The lipid mixture was then deposited as a thin film in a round-bottom flask, and a rotary evaporator was applied to the dichloromethane under a reduced pressure of $35 \pm 1^{\circ} \mathrm{C}$; this process continued for $1 \mathrm{hr}$ to ensure the total removal of all solvent traces. The mixture was then streamed with $\mathrm{N}_{2}$ gas, closed using plastic wrap, and stored at a low temperature for $24 \mathrm{hrs}$. The lipid film was hydrated in a $20 \mathrm{~mL}$ phosphate buffer solution ( $\mathrm{pH} 7.4$ ) that contained $30 \%$ ethanol by gently mixing it for 1 $\mathrm{hr}$ at room temperature and sonicating the solution for an additional 5 minutes. The sonicated vesicles were then extruded through $100 \mathrm{~nm}$ polycarbonate membranes for further size reduction.

\section{Transethosome characterization}

Particle size and zeta potential

A determination of the particle size, particle distribution, and zeta potential was accomplished via the DLS method using a particle size analyzer (Table 1). Two drops of suspension were dissolved in $10 \mathrm{~mL}$ of distilled water and then tested in the particle size analyzer (Malvern Zetasizer).

\section{Morphological characterization}

The morphology of vesicles was observed using a JEM-1400 TEM (Jeol Ltd., Tokyo, Japan) with an accelerating voltage of $80 \mathrm{kV}$. A drop of diluted dispersion (1:10) was applied to a film-coated copper grid, which was covered with carbon film and directly examined under the TEM.

\section{Deformability index}

The flexibility of the vesicle was measured using the extrusion method.

Table 1: Formulation of transethosome

\begin{tabular}{ll}
\hline Material & F1 (\%) \\
\hline Capsaisin & 0.5 \\
Phospholipon 90G & 2.5 \\
Span 80 & 0.44 \\
Ethanol:buffer phosphate (3:7) & Ad 100 \\
\hline
\end{tabular}

Table 2: The physicochemical properties of the prepared transethosome

\begin{tabular}{lll}
\hline Characteristics & Thin film method & Direct method \\
\hline Particle size $(\mathrm{nm})$ & $174.9 \pm 2.02$ & $200.7 \pm 2.06$ \\
PDI & $0.266 \pm 0.01$ & $0.297 \pm 0.03$ \\
Zeta potential & $-53.2 \pm 5.02$ & $-30.9 \pm 0.87$ \\
\hline PDI: Polydisersity index &
\end{tabular}

PDI: Polydispersity index
Transethosome suspensions were allowed to pass through microporous filters (including $0.1 \mu \mathrm{m}$ polycarbonate membranes) using a mini extruder set device. After passing through the membrane, particle sizes were noted and calculated using Formula 1.

$$
\mathrm{D}=\mathrm{J}\left(\frac{\mathrm{rv}}{\mathrm{rp}}\right)^{2}
$$

D=Deformability index,

$\mathrm{J}=$ Total suspensions allowed to pass through the membrane over 5 minutes $(\mathrm{mL})$,

$\mathrm{rv}=$ Particle size of the transethosome allowed to pass through the membrane (nm),

$\mathrm{rp}=$ Membrane pore size $(\mathrm{nm})$.

\section{Entrapment efficiency}

Entrapment efficiency was determined via the centrifuge method using a 5000 Da filter at $6000 \mathrm{rpm}$ for $3 \mathrm{hrs}$; this allowed researchers to measure the total amount of capsaicin entrapped within the residue, which had been split by the methanol. The amount of drugs present in the substance was quantified using a Spectro UV-Vis at $281 \mathrm{~nm}$. Entrapment efficiency was measured using Formula 2.

$\% \mathrm{EE}=\frac{\mathrm{C}_{\text {trapped }}}{\mathrm{C}_{\text {total }}} \times 100 \%$

$\mathrm{EE}=$ Entrapment efficiency (\%),

$\mathrm{C}_{\text {total }}=$ Total concentration of active compounds in the transethosome $(\mu \mathrm{g} / \mathrm{mL})$,

$\mathrm{C}_{\text {trapped }}=$ Measured concentration of entrapped active compounds $(\mu \mathrm{g} / \mathrm{mL})$.

\section{Gel preparation}

The gel was prepared using a dispersion of carbomer in distilled water; this substance was stirred until the carbomer was completely dispersed. Triethanolamine and propylene glycol were added to the gel base carbomer, which was stirred at $1500 \mathrm{rpm}$ until a thick gel base was formed. After the gel mass was created, capsaicin transethosome was added to the gel using a homogenizer; the gel was then mixed at a speed of $500 \mathrm{rpm}$ for 15 minutes. For the non-transethosome gel, capsaicin was dissolved in ethanol and then added to the gel base using the homogenizer.

\section{Transethosome gel evaluation}

The product was evaluated via tests of organoleptic qualities, homogeneity, $\mathrm{pH}$, viscosity, and physical stability at low temperatures $\left(4 \pm 2^{\circ} \mathrm{C}\right)$, room temperature $\left(28 \pm 2^{\circ} \mathrm{C}\right)$, and high temperatures $\left(40 \pm 2^{\circ} \mathrm{C}\right)$; tests were conducted for 8 weeks, with a 2-week interval between each observation and cycling test.

\section{In vitro skin permeation}

The in vitro permeation experiments were conducted using the Franz diffusion cells of the abdominal skin of Sprague Dawley rats (2-3 months old); notably, the fur of these rats had been shaved. The skin was then soaked in a phosphate buffer with a pH of 7.4 for 30 minutes and then stored at $5^{\circ} \mathrm{C}$. It is important to note that the skin was able to be used for $24 \mathrm{hrs}$. The diffusion cell area was $2.01 \mathrm{~cm}^{2}$, and the compartment volume was $15 \mathrm{~mL}$. The receptor compartment was filled with a phosphate buffer ( $\mathrm{pH}$ of 7.4) and ethanol (1:1); the temperature was held at $37 \pm 0.5^{\circ} \mathrm{C}$ and stirred via a magnetic stirrer at $300 \mathrm{rpm}$. Then, the abdominal skin was placed between the donor and receptor compartments with the stratum corneum position facing upward. A 1-g gel sample was applied to the skin surface. Then, at 10, 30, 60, 90, 120, $180,240,300,360,420$, and 480 minutes (until $24 \mathrm{hrs}$ had passed),we collected $3 \mathrm{~mL}$ from the receptor compartment using a syringe and 
replaced it with a phosphate buffer $(\mathrm{pH} 7.4)$ and ethanol mixture of the same volume. The sample was analyzed using a spectrophotometer UV-Vis at a wavelength of $281.0 \mathrm{~nm}$. This observation was conducted 3 times. The amount of capsaicin that penetrated the skin per diffusion area was measured using Formula 3.

$\mathrm{Q}=\frac{\left[\mathrm{Cn} . \mathrm{V}+\sum_{\mathrm{i}=1}^{\mathrm{n}-1} \mathrm{C} . \mathrm{S}\right]}{\mathrm{A}}$

$\mathrm{Q}=$ Total capsaicin accumulation that penetrated the skin per diffusion area $\left(\mu \mathrm{g} / \mathrm{cm}^{2}\right)$,

$\mathrm{Cn}=$ Capsaicin concentration $(\mu \mathrm{g} / \mathrm{mL})$ atn sampling minute,

$\mathrm{V}=$ Volume of Franz cell diffusion

$\sum_{\mathrm{i}=1}^{\mathrm{n}-1}=$ Total capsaicin concentration $(\mu \mathrm{g} / \mu \mathrm{L})$ during the first

sampling (at 10 minutes) until n minutes,

$\mathrm{S}=$ Sampling volume $(3 \mathrm{~mL})$,

$\mathrm{A}=$ Membrane area $\left(2.01 \mathrm{~cm}^{2}\right)$.

Then, the total amount of capsaicin accumulation that penetrated $(\mu \mathrm{g})$ the skin per diffusion area $\left(\mathrm{cm}^{2}\right)$ was measured against the time (hour), and a graph was constructed. The drug flux (based on Fick's law) was then measured using Formula 4.

$J=\frac{M}{S \times t}$

$\mathrm{J}=$ Flux $\left(\mu \mathrm{g} \mathrm{cm}^{-2} \mathrm{hr}^{-1}\right)$,

$\mathrm{M}=$ Total capsaicin accumulation that passed through the membrane $(\mu \mathrm{g})$,

$\mathrm{S}=$ Diffusion area $\left(\mathrm{cm}^{2}\right)$,

$\mathrm{t}=$ Time (hour),

Using the accumulation graph equation, we obtained the flux value; then, we developed a flux ( $\mu \mathrm{g} \mathrm{cm}^{-2} \mathrm{hr}^{-1}$ ) profile against the time (hour).

\section{RESULTS AND DISCUSSION}

\section{Characterization of transethosome}

\section{Particle size and zeta potential measurement}

Particle size can be determined by measuring random changes in the intensity of light that is scattered by a suspension or solution. Small particles in suspension undergo random thermal movements known as Brownian motions, and the polydispersity index (PDI) value demonstrates the distribution size of the total nanoparticle. PDI values of $<0.7$ indicate that the sample had a monodisperse size distribution. In addition, zeta potential is a measure of the charge on the surface of a particle in a specific liquid medium [8]. Stable nanoparticle suspensions should have a zeta potential value of $<-30 \mathrm{mV}$ or more than $+30 \mathrm{mV}$ [9]. Thus, suspensions must have a higher repulsive force and a stable system to prevent the aggregation of the particle.

\section{Morphology characterization}

Morphology tests of the vesicle formations were performed using TEM; these tests showed that the vesicles had a spherical and unilamellar structural form, as shown in Figs. 1 and 2.

\section{Deformability index}

The results were expressed in terms of the elasticity index using Formula 1. The deformability index value obtained from the thin layer method was 3.06, while the same value for the direct method was 3.86 . The higher the deformability index, the more flexible the transethosome.

\section{Entrapment efficiency}

Results showed that in formulations developed using the thin layer method, the entrapment efficiency of the entrapped compound was
$84.85 \pm 1.15 \%$, while in formulations created via the direct method, that figure was $84.24 \pm 1.27 \%$. Overall, the thin film method led to greater $\mathrm{EE} \%$ values; this may be attributed to the formation of a thin film with a large surface area (developed according to the rotary evaporation method), which enabled the complete hydration of the vesicles [10].

\section{Physical evaluation of the gel}

Physical stability tests of the gel compounds were conducted at different temperatures to compare their physical stability. Stability testing was performed by observing organoleptic qualities and $\mathrm{pH}$ every 2 weeks for 8 weeks. Both the transethosomegel and the nontransethosome gel showed no changes in organoleptic qualities. For each preparation, $\mathrm{pH}$ testing revealed $\mathrm{pH}$ levels of 5.82 and 5.75. The $\mathrm{pH}$ was decreased after 8 weeks, though it remained at a balanced level for skin (4.5-6.5) [11]. Viscosity measurements showed that both gel preparations had pseudoplastic thixotropic flow rheology characteristics, which are described in Figs. 3 and 4. In addition, homogeneity tests showed that both gel compounds were homogeneous. Finally, tests of cycling stability were performed in six cycles; results showed no syneresis in either compound.

\section{In vitro skin permeation}

The levels of capsaicin penetration accumulation in the mice skin membranes after $8 \mathrm{hrs}$ were $1549.68 \pm 49.6$ and $846.05 \pm 10.1 \mu \mathrm{g} / \mathrm{cm}^{2}$ for the transethosome gel and non-transethosome gel preparations, respectively (Fig. 5). The percentage results of penetration accumulation

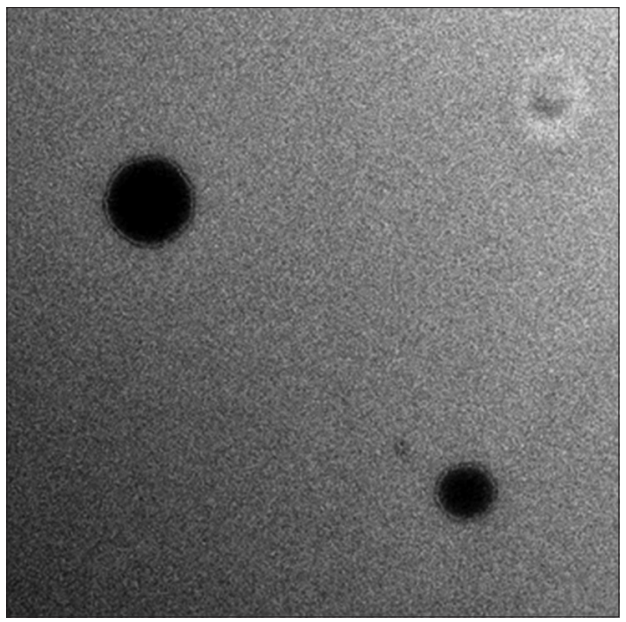

Fig. 1: The transmission electron microscope results of the thin film method

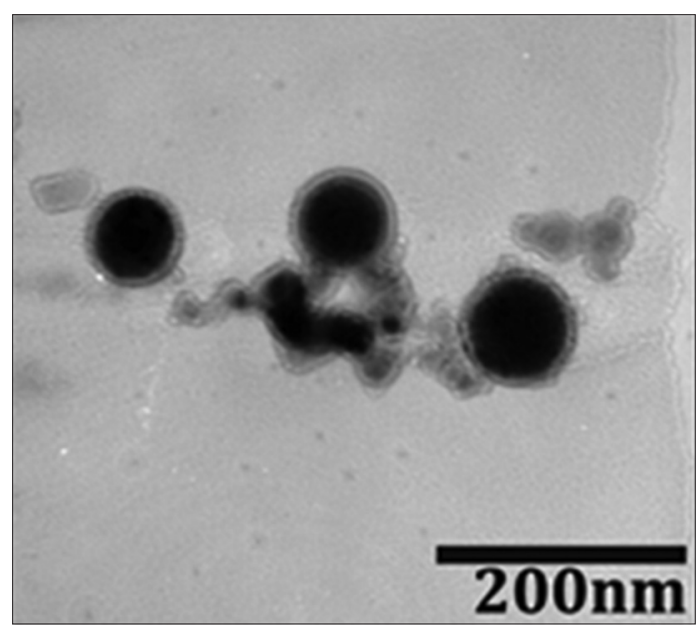

Fig. 2: The transmission electron microscope results of the direct method 


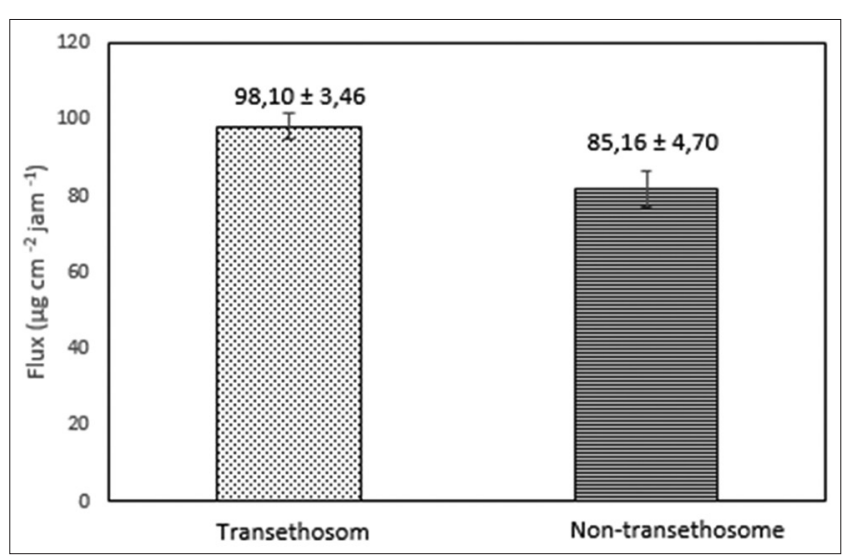

Fig. 3: Average penetration flux of capsaicin using transethosome gel and non-transethosome gel

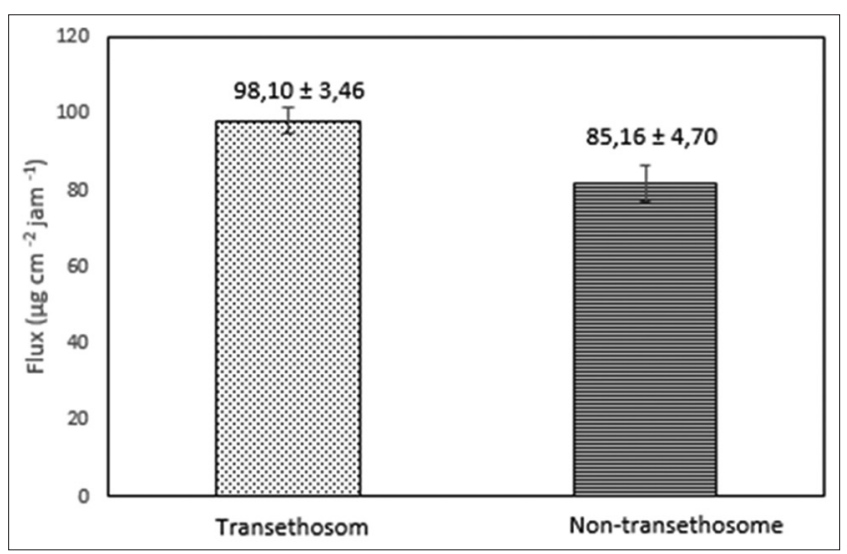

Fig. 4: Average penetration flux of capsaicin from transethosome gel and non- transethosome gel

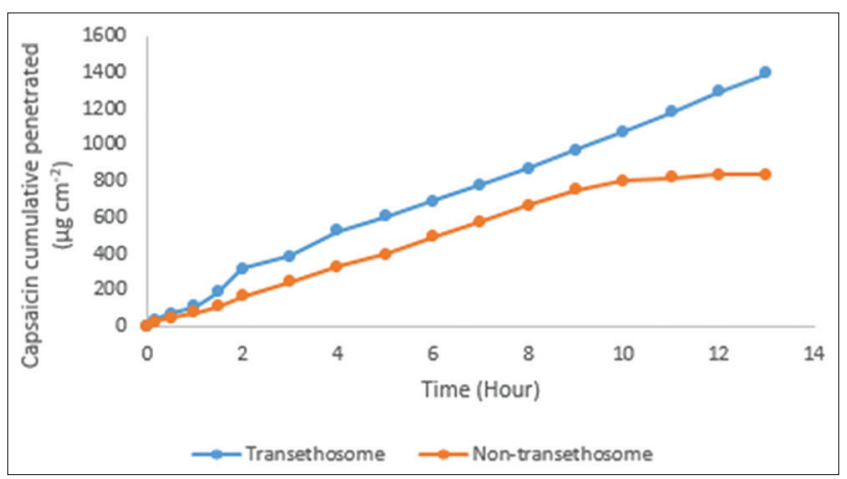

Fig. 5: Penetration profile of capsaicin using transethosome gel and non-transethosome gel

measurements after $13 \mathrm{hrs}$ were $60.15 \pm 0.2 \%$ and $42.89 \pm 0.42 \%$ for the transethosome gel and non-transethosome gel preparations, respectively. The total amount of penetrated and accumulated capsaicin was plotted against time, and a linear regression equation was developed to determine the capsaicin flux from each formulation. According to Fick's first law, flux can be obtained from the slope of Fig. 5, which illustrates the flux value obtained in a steady state. Fig. 3 describes a comparison of the flux values of each preparation. The flux values of the transethosome gel and non-transethosome gel preparations were $98.10 \pm 3.46$ and $85.16 \pm 4.70 \mu \mathrm{g} \mathrm{cm}^{-2} \mathrm{jam}^{-1}$, respectively.

From these results, it is clear that the transethosome gel substance provided a higher flux than did the non-transethosome gel product.
In addition, the rate of penetration was faster in the transethosome capsaicin gel preparation than in the non-transethosome capsaicin gel formulation. The in vitro skin permeation rate and the cumulative amount of capsaicin that permeated the skin after $13 \mathrm{hrs}$ was highest in the transethosome gel product. The higher permeation of transethosomes may be the result of a combination of the effects of lipid vesicles, ethanol, and EAs. Other factors that may affect drug absorption through the skin are the viscosity of the preparation, the dissolution of a drug in the carrier, the diffusion of a dissolved drug from the carrier to the surface of the skin, and the penetration of drugs through the skin, especially the stratum corneum layer [12]. The partition coefficient of a drug can also affect its rate of penetration. It must be noted that capsaicin is not soluble in water; thus, the dissolution of capsaicin using a standard gel preparation was lower than when a transethosome gel form was utilized.

\section{CONCLUSION}

According to the results of this study, it can be concluded that the thin layer method provided better characteristics as compared to the direct method. Using the thin layer method, the resulting particle size was $174.9 \pm 2.02 \mathrm{~nm}$, and the entrapment efficiency was $84.85 \pm 1.15 \%$. The gel preparation was found to be stable at any temperature; stability was also demonstrated during cycling tests and during storage, and ultimately a pseudoplastic thixotropic rheology was provided for gels viscosity. Penetration tests of the gel preparations revealed that the penetration rate of capsaicin was $1549.68 \pm 49.6 \mu \mathrm{g} / \mathrm{cm}^{2}$ and $846.05 \pm 10.1 \mu \mathrm{g} / \mathrm{cm}^{2}$ for the transethosome gel formula and the non-transethosome gel formulation, respectively. In addition, the accumulative percentages of active substance were $60.15 \pm 0.02 \%$ and $42.89 \pm 0.42 \%$. Penetration testing ultimately showed that transethosome capsaicin gel was better able to permeate the rat skin than was the non-transethosome capsaicin gel.

\section{REFERENCES}

1. Kimura H, Ogawa S, Sugiyama A, Jisaka M, Takeuchi T, Yokota K. Anti-obesity effects of highly polymeric proanthocyanidins from seed shells of Japanese horse chestnut (Aesculus turbinata Blume). Food Res Int 2011;44(1):121-6.

2. Whiting S, Derbyshire E, Tiwari BK. Capsaicinoids and capsinoids. A potential role for weight management? A systematic review of the evidence. Appetite 2012;59(2):341-8.

3. Sarwa KK, Mazumder B, Rudrapal M, Verma VK. Potential of capsaicin-loaded transfersomes in arthritic rats. Drug Deliv 2015;22(22):638-46.

4. Ascenso A, Raposo S, Batista C, Cardoso P, Mendes T, Praça FG, et al. Development, characterization, and skin delivery studies of related ultradeformable vesicles: Transfersomes, ethosomes, and transethosomes. Int J Nanomedicine 2015;10:5837-1.

5. Song CK, Balakrishnan P, Shim CK, Chung SJ, Chong S, Kim DD. A novel vesicular carrier, transethosome, for enhanced skin delivery of voriconazole: Characterization and in vitro/in vivo evaluation. Colloids Surf B Biointerfaces 2012;92:299-304.

6. Ma M, Wang J, Guo F, Lei M, Tan F, Li N. Development of nanovesicular systems for dermal imiquimod delivery: Physicochemical characterization and in vitro/in vivo evaluation. J Mater Sci Mater Med 2015;26(6):191.

7. Shaji J, Garude S. Transethosomes and ethosomes for enhanced transdermal delivery of ketorolac tromethamine. Comp Assess 2014;6(4):1-6.

8. A Guidebook to Particle Size Analysis. Available from: https://www. horiba.com/fileadmin/uploads/Scientific/Documents/PSA/PSA Guidebook.pdf; 2014.

9. Chen Y, Wu Q, Zhang Z, Yuan L, Liu X, Zhou L. Preparation of curcumin-loaded liposomes and evaluation of their skin permeation and pharmacodynamics. Molecules 2012;17(5):5972-87.

10. El Zaafarany GM, Awad GA, Holayel SM, Mortada ND. Role of edge activators and surface charge in developing ultradeformable vesicles with enhanced skin delivery. Int J Pharm 2010;397(1-2):164-72.

11. Tranggoono RI, Latifah F. Handbook of Cosmetics Study. Jakarta: Gramedia; 2007.

12. Barry BW. Novel mechanisms and devices to enable successful transdermal drug delivery. Eur J Pharm Sci 2001;14(2):101-4. 